\title{
Covid-19: skin damage with prolonged wear of FFP3 masks
}

\author{
Anna Payne core surgical trainee \\ Department of Plastic and Reconstructive Surgery, Barts Health NHS Trust, The Royal London Hospital, London E1 1FR, UK
}

Sayburn refers to Public Health England guidance recommending the use of FFP3 masks when performing aerosol generating procedures and in high risk units where such procedures are performed. ${ }^{1}$ Thus healthcare workers should wear FFP3 masks in intensive care units housing patients with covid-19, which means several hours of continuous wear.

I have recently been redeployed to the intensive care unit, and many of my colleagues have experienced discomfort and pressure damage to the skin, particularly at the nasal bridge, after prolonged wear of FFP3 masks. Despite regular moisturising and mask-free breaks, some have had skin damage consistent with grade 2 pressure ulcers. $^{2}$

Facial skin breakdown is a known complication for patients undergoing non-invasive ventilation. Suggestions for pressure ulcer prevention in these patients include provision of a well fitting mask and adjustment of strap tension to reduce pressure on the skin. ${ }^{3}$ These adjustments are not possible with FFP3 masks.

Protective hydrocolloid dressings have been shown to prevent the development of pressure ulcers in patients undergoing non-invasive ventilation ${ }^{4}$ and are commonly used on grade 1 pressure ulcers and skin at risk of breakdown to prevent progression. ${ }^{5}$ In FFP3 wearers, a strip of hydrocolloid dressing over the nasal bridge should not impair the mask seal and would probably improve comfort and reduce skin damage. This should be considered in those wearing masks for longer than two hours and in those with pre-existing skin damage. This, in addition to regular moisturising and mask-free breaks, is likely to improve comfort and reduce pressure ulcer formation among healthcare workers.

Competing interests: None declared.

Full response at: https://www.bmj.com/content/369/bmj.m1297/rr-3.

1 Sayburn A. Are UK doctors getting sufficient protective equipment against covid-19?BM 2020;369:m1297. 10.1136/bmj.m1297 32241766

2 NICE. Pressure ulcers (QS89). 2015. https://www.nice.org.uk/guidance/qs89/resources/ pressure-ulcers-pdf-2098916972485

3 Brill AK. How to avoid interface problems in acute noninvasive ventilation. Breathe (Sheff) 2014;10:230-4210.1183/20734735.003414

4 Weng $\mathrm{MH}$. The effect of protective treatment in reducing pressure ulcers for non-invasive ventilation patients. Intensive Crit Care Nurs 2008;24:295-9.

10.1016/j.iccn.2007.11.005 18242994

5 Wick G. A guide to the treatment of pressure ulcers from grade 1 to grade 4 . Wound Essentials 2007;2:106-13.

Published by the BMJ Publishing Group Limited. For permission to use (where not already granted under a licence) please go to http://group.bmj.com/group/rights-licensing/ permissions 